\title{
FRACTOGRAPHIC ANALYSIS OF MONOLITHIC AND BILAYERED ZIRCONIA AFTER THERMO-MECHANICAL FATIGUE AND FRACTURE STRENGTH TEST
}

\author{
Abdulmuein Ahmad Alzhairi", Ahmed Mohamed Hamdy** and Faisal Safwat Hamza***
}

\begin{abstract}
Objective: To study the fracture origin of different zirconia restorations.

Materials and Methods: A first upper premolar sound natural tooth was prepared and duplicated into epoxy resin die. Twenty-one full coverage crowns were fabricated and divided into three groups according to type of ceramic material; super high translucent monolithic zirconia (Zolid fx) group (A), super translucent monolithic zirconia (STML Katana) group (B), and zirconia core (Ceramill zi) with hand-layered veneering porcelain (Vita VM9) group (C). Crowns were cemented with selfadhesive resin cement. All samples were first subjected to thermal cycling $\left(5^{\circ}-55^{\circ} \mathrm{C} / 10,000\right.$ cycle $)$ and then to chewing simulator $(240,000$ cycles, $50 \mathrm{~N})$. After fracture resistance test, fractographic method was used to analyze the fractured samples.
\end{abstract}

Results: The fracture origin of all studied groups was similar with crack origin located at occlusal surface (cone crack). Crack origins were indicated with mirror regions with appearing lines of hackle.

Conclusion: The fracture origin was found to be dependent on the fracture resistance technique rather than the material itself.

KEYWORDS: Fractographic analysis, zirconia, artificial aging.

\section{INTRODUCTION}

Monolithic zirconia was introduced to overcome the bilayered zirconia problems, such as chipping or delamination, and to achieve the greatest strength within ceramic restoration ${ }^{(1)}$.
Fractographic analysis provides reliable facts about the fracture component in order to investigate the circumstances surrounding a failure event with the expectation of eventually explaining the cause of failure whether it was a result of material deficiency (fabrication process), design deficiency,

\footnotetext{
* Msc, Fixed Prosthodontics, Faculty of Dentistry, MAS University, Cairo, Egypt.

** Professor, Professor of Fixed Prosthodontics, Faculty of Dentistry, MSA University,Cairo, Egypt.

*** Assistant Professor, Fixed Prosthodontics, Faculty of Dentistry, MSA University, Cairo, Egypt.
} 
or in situ stress induced conditions ${ }^{(2)}$. The first use of clinical fractography in the dental literature involving ceramic clinical failures goes back to 1989 and $1990^{(3)}$. Fractography includes the examination of fracture surfaces and its features resulting from the interaction of the advancing crack with the microstructure of the material and the stress fields ${ }^{(2)}$.

The fractured ceramics may give features like compression curl, hackle, wake hackle, twist hackle, mirror and arrest line. Those features contribute to identify the failure origin and the direction of crack propagation (dcp) to finally state the specific reasons for failure ${ }^{(4)}$. Ceramics are strong under compressive strength and brittle under tensile stress. Thus, upon failure, brittle fractures commonly occur with approximately $0.01 \%$ of elastic elongation and no detectable plastic deformation ${ }^{(3)}$. This gives rise to typical fracture patterns ${ }^{(5)}$.

The aim of this study was to compare the fracture origin of fatigued restoration of different types (monolithic and bilayered zirconia) after fracture strength test. The null hypothesis to be tested was that the fracture origin of zirconia would not be affected by the fabrication technique.

\section{MATERIALS AND METHODS}

The natural sound upper first premolar tooth was prepared using the CNC milling machine with $1.2 \mathrm{~mm}$ chamfer finish line and occlusal reduction $1.5 \mathrm{~mm}$, then the prepared tooth was duplicated into 21 epoxy resin dies. Twenty-one epoxy dies were randomly divided into three groups (7 each) according to material (Table 1). Group (A) was super high translucent monolithic zirconia, Group (B) super translucent monolithic zirconia and Group (C) bilayered zirconia (control group).

After scanning of the master die, two designs were done. First design was for group $(A, B)$ with occlusal thickness of $1.5 \mathrm{~mm}$ and axial wall thickness of $1.2 \mathrm{~mm}$, second design was for group (C) with $0.5 \mathrm{~mm}$ coping thickness. All groups were dry milled with the same five axis milling machine.
TABLE (1): Samples grouping

\begin{tabular}{ccc}
\hline Groups & Abbreviation & No. of samples \\
\hline Full monolithic restoration & A & 7 \\
\hline Full monolithic restoration & B & 7 \\
\hline Bilayered restoration & C & 7 \\
\hline
\end{tabular}

The full contoured crowns were sandblasted on the external surface, cleaned with a steam cleaner, and glazed. Silicon index impression mold was taken from one finalized full contoured restoration in order to duplicate the anatomy with total dimensions of $1.5 \mathrm{~mm}$ occlusally and $1.2 \mathrm{~mm}$ cervically to standardize the veneered crowns final thickness ${ }^{(6,7)}$. The silicon mold was split into two halves (buccal-lingual). The thickness of veneering porcelain was $0.7 \mathrm{~mm}$ cervically and $1.0 \mathrm{~mm}$ occlusally as recommended by the manufacturer's instructions ${ }^{(8)}$, add-on glazing was applied over the bilayered zirconia crowns. Firing cycle in special furnace was done according to the manufacturer's instructions.

After sandblasting of the internal surface, all restorations of each group were cemented onto resin duplicating dies with self-adhesive resin cement (RelyX U200, 3M ESPE, Germany) using customized loading device of $5 \mathrm{~kg}$ for 5 minutes ${ }^{(9,10)}$.

After one week of distilled water storage at room temperature ${ }^{(11)}$, the samples were subjected to aging with thermocycling ( SD Mechatronik Thermocycler, Munich, Germany) of 10,000 cycles $\left(5-55^{\circ} \mathrm{C}\right)$ in distilled water ${ }^{(12)}$ then subjected to 240,000 mechanical cycles (CS-4.4, SD Mechatronik, Munich, Germany) of $5 \mathrm{~kg}$ load in distilled water to simulate one year of service ${ }^{(13)}$.

Fracture resistance test was performed for all samples with cross-head speed $0.5 \mathrm{~mm} / \mathrm{min}$ till failure in a universal testing machine (Model 3345, Instron Industrial Products, Norwood, MA, USA) ${ }^{(9)}$. 
After the fracture resistance was done, the fractured samples were analyzed by fractographic methods start with stereomicroscope (MA100 Nikon Stereomicroscope, Japan) and then with scanning electron microscope (SEM Model Quanta 250FEG, Thermo Fisher Scientific, Netherlands) to detect the fracture origin and crack propagation (14). Before scanning with SEM, the fragments were cleaned in an ultrasonic alcohol bath for $10 \mathrm{~min}$ ${ }^{(15)}$. The fracture origins were classified into either from occlusal surface (cone crack) or from internal surface of the crown (radial crack) or at crown margin ${ }^{(16)}$.

Categorical data were presented as frequency and percentage values and analyzed using Fisher's exact test. Differences between groups were tested for statistical significance by use of one-way analysis of variance ANOVA test. The significance level was set at $\mathrm{p} \leq 0.05$.

\section{RESULTS}

\section{Fractographic results}

Frequencies (n) and Percentages (\%) of fracture origin in different groups were presented in (Table 2). SEM images of all samples revealed fracture originating from the occlusal surface. Crack origins were indicated with mirror regions where the appearing lines of hackle help in determining the crack propagation (Figs 1, 2 and 3).

TABLE (2): Frequencies (n) and Percentages (\%) of fracture origin in different groups

\begin{tabular}{|c|c|c|c|c|c|}
\hline Fracture origin & & A & B & C & p-value \\
\hline \multirow{2}{*}{ Occlusal surface (cone crack) } & $\mathbf{n}$ & 7 & 7 & 7 & \multirow{6}{*}{ NA } \\
\hline & $\%$ & $100.0 \%$ & $100.0 \%$ & $100.0 \%$ & \\
\hline \multirow[b]{2}{*}{ Internal surface of the crown (radial crack) } & $\mathbf{n}$ & 0 & 0 & 0 & \\
\hline & $\%$ & $0.0 \%$ & $0.0 \%$ & $0.0 \%$ & \\
\hline \multirow{2}{*}{ Crown margin } & $\mathbf{n}$ & 0 & 0 & 0 & \\
\hline & $\%$ & $0.0 \%$ & $0.0 \%$ & $0.0 \%$ & \\
\hline
\end{tabular}
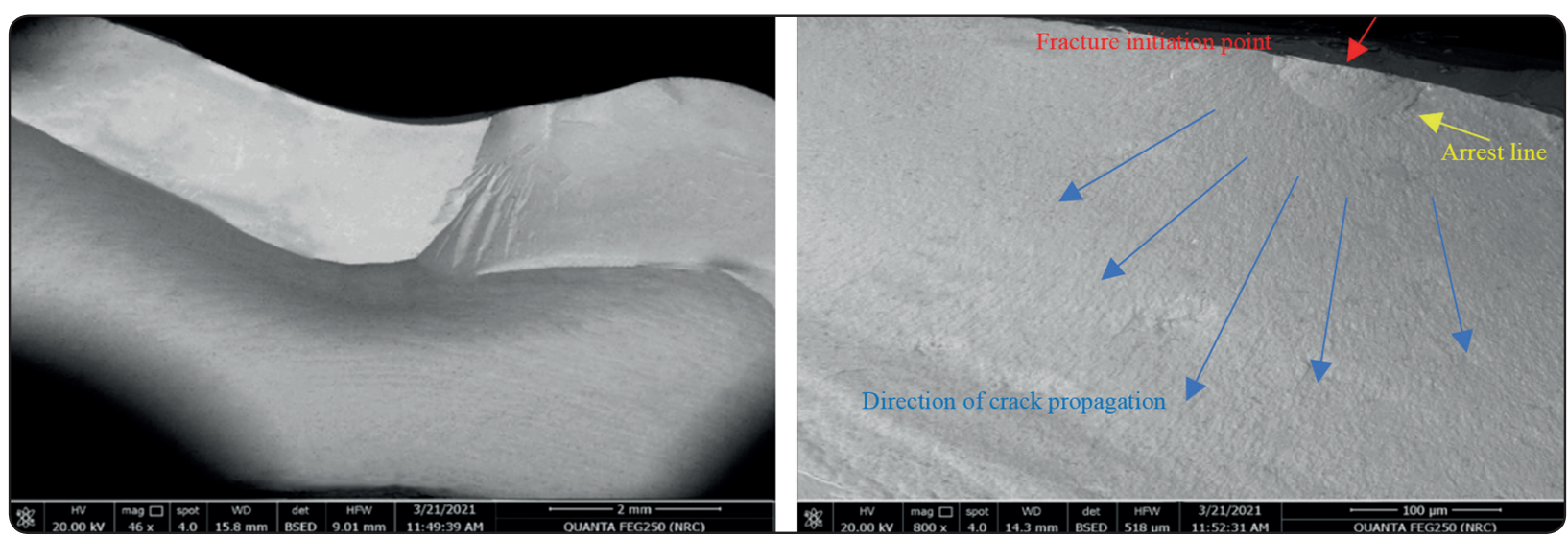

Fig. (1): Fractured monolithic zirconia sample group (A) viewed at 46X and 800X under SEM exhibiting fracture initiation point, arrest line and hackles lines. 


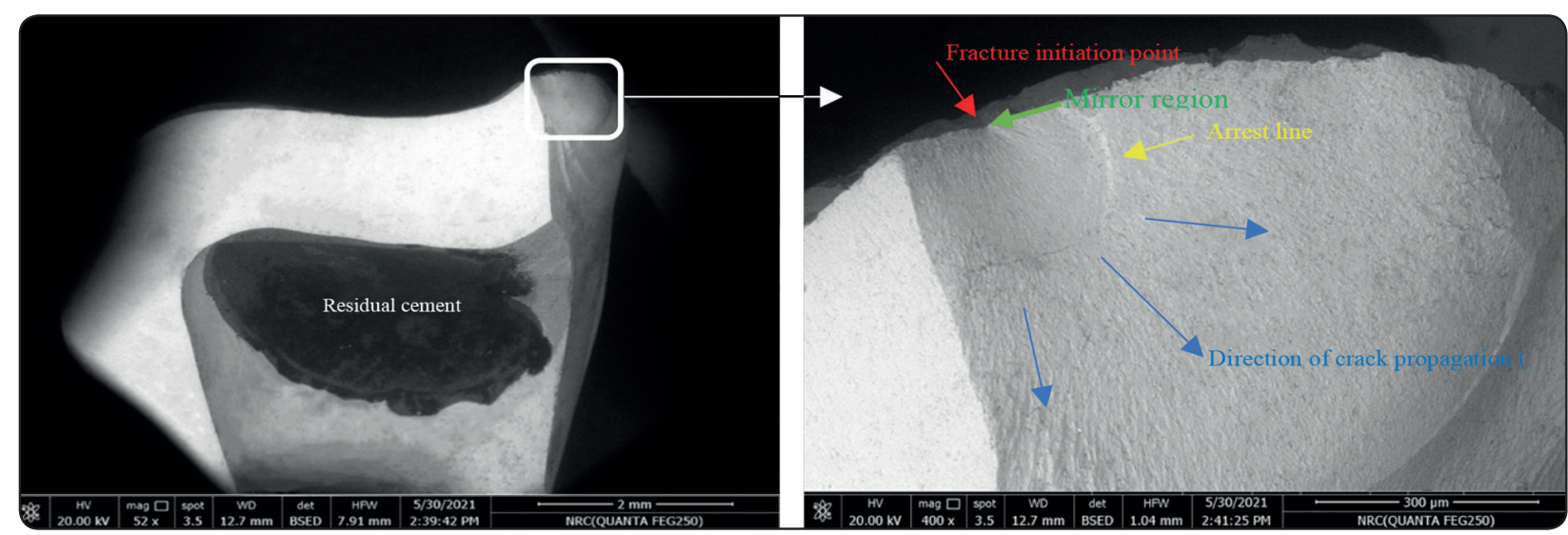

Fig. (2): Fractured monolithic zirconia sample group (B) viewed at 52X and 400X under SEM exhibiting fracture initiation point, arrest line and hackles lines.

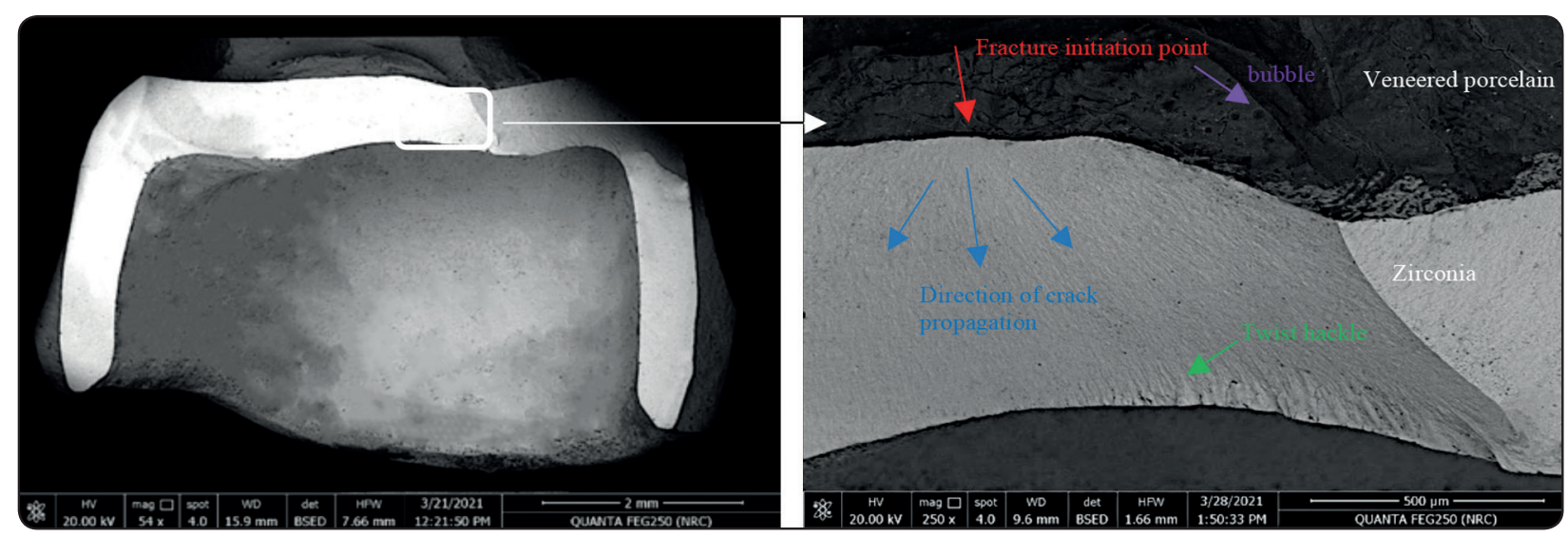

Fig. (3): Fractured bilayered zirconia sample group (C) viewed at 54X and 250Xunder SEM exhibiting fracture initiation point, twist hackles and hackles lines.

\section{DISCUSSION}

The aim of the present study was to compare the fracture origin of different types of monolithic and bilayered zirconia restoration after thermomechanical fatigue and fracture strength test.

The master die was prepared with computerized numerical control (CNC) machine after designing of preparation to standardize reduction ${ }^{(17)}$. Epoxy resin dies were used to substitute the natural abutments because of its close modulus of elasticity (11.8GPa) to that of the dentine $(18.6 \mathrm{GPa}){ }^{(18)}$. The epoxy resin dies have successfully served to standardize the master die dimensions ${ }^{(19)}$.
SEM images of the analyzed bilayered zirconia samples revealed that the fracture was originating from the occlusal surface (cone crack). Crack origins were indicated with mirror regions where the appearing lines of hackle or wake hackle help in determining the crack propagation. The possible explanation for this may be due to contact damage at the occlusal loading point as the restorations were loaded at the occlusal surface with a steel ball $5 \mathrm{~mm}$ in diameter and may thus have limited clinical significance.

Our results agreed with Mogahed et al., ${ }^{(20)}$ who found concave orientation of the arrest lines in the chipped veneering layer which indicated that the 
damage started at the occlusal surface similar to the origin of fracture in the current study.

Our results disagreed with Øilo et al., (21) who reported that the margins flaws can initiate core fractures during clinical use, as it was found that the failure origin of molar bi-layered zirconia restorations were located at the cervical margin of proximal area. This could be related to the used $30 \mathrm{~mm}$ diameter steel ball during fracture resistance test that have created hoop stresses at the margin. Also, Oilo and Gjerdet ${ }^{(22)}$ noted same type of stresses at the restoration margin, they explained that this could be as a result of difference of modulus of elasticity between dentine and ceramic restorations that leaded to compression stresses at restoration margin. Moreover, Aboushelib et al., (23) compared the fracture origin of in-vivo and invitro restorations in which it was found that the fracture origin of bi-layered zirconia restorations in-vivo located at the internal surface (radial crack) that was related to the CAD-CAM milling defects, while in-vitro it was present at the occlusal surface as cone crack as a result of the loading conditions that cannot occur intraorally.

Also, the results of our study disagreed with Skjold et al., (24) who showed that $0.5 \mathrm{~mm}$ thickness zirconia core without veneering material experienced internal surface cracks because of the limited occlusal thickness of zirconia core together with the wedging action created by cylindrical indenter over both the zirconia core and the underlying cement that crashed immediately under tensile stresses followed by cracks at the internal surface of zirconia core. The possible explanation for this may be due to the limited thickness of the restoration used while in our study veneered core showed increased fracture load during fracture resistance test.

SEM images of the analyzed monolithic zirconia restorations either group (A) or group (B) revealed that the fracture is originating from the occlusal surface (cone crack). The possible explanation for this may be due to it's increased thickness and the possibility of presence of microcracks in the sublayer zone which result in occlusal initiation of the crack. Also, it could be related to complex occlusal morphology of upper premolar because of it's cusp steepness which increased the possibility of fracture under occlusal loads. Result of the current study is in agreement with those of Findakly and Jasim ${ }^{(25)}$ and Spitznagel et al., ${ }^{(26)}$.

Our results contradicted with Mogahed et al., ${ }^{(20)}$ where monolithic zirconia restorations showed cementation internal surface cracks (radial cracks) due to higher elastic modulus of monolithic zirconia compared to other groups. The critical load required to initiate radial crack depends on the elastic modulus difference between supporting structure material and restoration material. The elastic modulus difference between restoration and supporting die is higher in case of monolithic zirconia crown which showed internal surface crack.

Also, our results disagreed with Skjold et al., (16) where monolithic zirconia restorations showed a fracture origin in cervical margin in the proximal area where the finish line curves toward the occlusal surface. The proximal region is the weakest part of the crown as the mesial and distal margins of a ceramic restoration exhibited highest stress values during compression. The possible explanation for this may be due to the presence of flaws distributed along the restoration margins as an intrinsic part of this restoration. Moreover, margin flaws will likely be more vulnerable to aging and thus more detrimental to strength because of the stress accumulations at the flaws. Despite of the presence of other previous studies of both clinical failures and in vitro failures have shown both flaw-induced fractures and fractures originating from apparently flawless margins.

The limitations of the present study were that it was in-vitro study in which not all in-vivo simulation conditions were applied like variation of mechanical forces, $\mathrm{pH}$ changes, presence of saliva 
and bacteria. Another limitation was that analyzing with long term thermomechanical fatigue duration might be necessary to obtain better evaluation of invitro studies. Further in-vivo trials with long term follow ups are encouraged.

\section{CONCLUSIONS}

Within the limitations of this study the following conclusions could be drawn:

1- Fabrication techniques of zirconia restoration does not affect the fracture origin.

2- The fracture origin was found to be dependent on the fracture resistance technique rather than the material itself.

\section{REFERENCES}

1. Agustín-Panadero R, Martínez RL, Solá-Ruíz MF, FonsFont A, Engra GG, Fernández-Estevan L. (2019). Are metal-free monolithic crowns the present of prosthesis? study of mechanical behaviour. Materials. 12(22): 3663-3671.

2. Scherrer SS, Quinn GD, Quinn JB. (2008). Fractographic failure analysis of a procera allceram crown using stereo and scanning electron microscopy. Dent Mater. 24(8): 1107-1113.

3. Scherrer SS, Lohbauer U, Bona AD, Vichi A, Tholey MJ, Kelly JR, Noort RV, Cesar PF. (2017). ADM guidanceceramics: guidance to the use of fractography in failure analysis of brittle materials. Dent Mater. 33(6): 599-620.

4. Lohbauer U, Amberger G, Quinn GD, Scherrer SS. (2010). Fractographic analysis of a dental zirconia framework: a case study on design issues. J Mech Behav Biomed Mater. 3(8): 623-629.

5. Shen JZ, Kosmač T. (2014). Advanced Ceramics for Dentistry 1 (ed). (78-97). Butterworth Heinemann, Elsevier Inc.

6. Lameira DP, Silva WAB, Silva FA, De Souza GM. (2015). Fracture Strength of Aged Monolithic and Bilayer Zirconia-Based Crowns. Biomed Res Int. 1-7.

7. Hemdan SS, Abd El-Aziz SA, El-Shrkawy ZR. (2019). Comparative Study Between Monolithic Translucent Zirconia (Y-TZP) and IPS Empress 2 in Marginal Fit and Fracture Strength. ADJ for girls. 6(4): 391-399.
8. Al-Wahadni A, Shahin A, Kurtz KS. (2016). Veneered zirconia-based restorations fracture resistance analysis. J Prosthodont. 27(7): 651-658.

9. Al-Joboury AIK, Zakaria MR. (2015). An evaluation of the influence of different finishing lines on the fracture strength of full contour zirconia CAD/CAM and heat press all-ceramic crowns. J Bagh Coll Dentistry. 27(1): 54-62.

10. Sorrentino R, Triulzio C, Tricarico MG, Bonadeo G, Gherlone EF, Ferrari M. (2016). In vitro analysis of the fracture resistance of CAD-CAM monolithic zirconia molar crowns with different occlusal thickness. J Mech Behav Biomed Mater .61: 328-333.

11. Sagsoz NP, Yanikoğlu N, Sagsoz O. (2016). Effect of die materials on the fracture resistance of $\mathrm{CAD} / \mathrm{CAM}$ monolithic crown restorations. Oral Health Dent Manag. 15(3): 165-168.

12. Gale MS, Darvell BW. (1999) Thermal cycling procedures for laboratory testing of dental restorations. J Dent. 27(2): 89-99.

13. Tekin YH, Hayran Y. (2020). Fracture resistance and marginal fit of the zirconia crowns with varied occlusal thickness. J Adv Prosthodont. 12(5): 283-290.

14. Scherrer SS, Quinn GD, Quinn JB. (2008). Fractographic failure analysis of a procera allceram crown using stereo and scanning electron microscopy. Dent Mater. 24(8): 1107-1113.

15. Belli R, Petschelt A, Lohbauer U. (2013). Thermal-induced residual stresses affect the fractographic patterns of zirconia-veneer dental prostheses. J Mech Behav Biomed Mater. 21: 167-177.

16. Skjold A, Schriwer C, Gjerdet NR \& Øilo M. (2020). Effect of artificial aging on high translucent dental zirconia: simulation of early failure. Eur J Oral Sci.128(6): 526-534.

17. Aqlan S, Elnaggar G, Kheiralla L. (2018). Fracture resistance of thin occlusal veneers made from hybrid ceramic (Cerasmart)- in vitro study. Al-Azhar J Dent Sci. 21(3): 293-297.

18. Yucel MT, Yondem I, Aykent F, Eraslan O. (2012). Influence of the supporting die structures on the fracture strength of all-ceramic materials. Clin Oral Invest. 16(4): 1105-1110.

19. Elgamma MA, Othman HI, Mohamed HR. (2018). Effect of two preparation designs and methods of construction on the fracture resistance of glass ceramic laminate veneers. Al-Azhar J Dent Sci. 21(4): 313-319. 
20. Mogahed MM, Shakal MA, Hasaneen FA. (2021). Comparative study of fracture resistance of different ceramic restorations. Egypt Dent J. 67(2):1563-1569.

21. Øilo M, Kvam K, Gjerdet NR. (2016). Load at fracture of monolithic and bilayered zirconia crowns with and without a cervical zirconia collar. J Prosthet Dent. 115(5): 630-636.

22. Øilo M, Gjerdet NR. (2013). Fractographic analyses of allceramic crowns: A study of 27 clinically fractured crowns. Dent Mater. 29(6):78-84.

23. Aboushelib MN, Feilzer AJ, Kleverlaan CJ. (2009). Bridging the gap between clinical failure and laboratory fracture strength tests using a fractographic approach. Dent Mater.
25(3): 383-391.

24. Skjold A, Schriwer C, Øilo M. (2019). Effect of margin design on fracture load of zirconia crowns. Eur J Oral Sci. 127(1): 89-96.

25. Findakly MB, Jasim HH. (2019). Influence of preparation design on fracture resistance of different monolithic zirconia crowns: A comparative study. J Adv Prosthodont. 11(6): 324-330.

26. Spitznagel FA, Röhrig S, Langner R, Gierthmuehlen PC. (2021). Failure load and fatigue behavior of monolithic translucent zirconia, picn and rapid-layer posterior single crowns on zirconia implants. Materials. 14(8): 1-15. 